Research Article

\title{
Study on Deformation Mechanism and Supporting Countermeasures of Compound Roofs in Loose and Weak Coal Roadways
}

\author{
Jianfeng Cui, ${ }^{1,2,3}$ Weijun Wang $\mathbb{D D}^{1,2,3}$ Chao Yuan $\mathbb{D}^{1,},{ }^{1,2,3}$ Liming Cao, ${ }^{3}$ Yuning Guo, ${ }^{3}$ \\ and Lei Fan $^{3}$ \\ ${ }^{1}$ Work Safety Key Lab on Prevention and Control of Gas and Roof Disasters for Southern Coal Mines, Xiangtan 411201, China \\ ${ }^{2}$ Hunan Key Laboratory of Safe Mining Techniques of Coal Mines, Xiangtan 411201, China \\ ${ }^{3}$ School of Resources, Environment and Safety Engineering, Hunan University of Science and Technology, Xiangtan 411201, China
}

Correspondence should be addressed to Chao Yuan; yuanchaozh1@126.com

Received 6 July 2020; Revised 26 August 2020; Accepted 26 October 2020; Published 12 November 2020

Academic Editor: Fengqiang Gong

Copyright (C) 2020 Jianfeng Cui et al. This is an open access article distributed under the Creative Commons Attribution License, which permits unrestricted use, distribution, and reproduction in any medium, provided the original work is properly cited.

\begin{abstract}
This paper considers the 333 return airway of the Gaokeng Coal Mine to analyze the deformation characteristics and failure mechanism of the surrounding rock of the composite roof for a loose and weak coal roadway. The reasons for the large deformation are explored and the superiority of the prestressed truss and anchor rope is compared to ordinary anchor cables from the perspective of mechanics to propose a targeted coal roadway support method. Sinking of the composite roof in the coal roadway is accompanied with a release and transfer of the surrounding rock stress. The pressure of the composite roof transfers to the roadway sides and intensifies the fracture process of the coal body. As a result, the ability to support the composite roof is weakened, and it further bends and sinks to form a vicious cycle that repeats itself. Therefore, the support of the composite roof in the coal roadway should consider the roof, roadway sides, and floor as a single unit to achieve the support goal of reinforcing the roadway sides and roof. Based on the above analysis, a comprehensive control technology with a truss and anchor rope is proposed as the main body and a bolt + anchor cable + metal network as the auxiliary. This technology can improve the integral bearing capacity of the composite roof, strengthen the roadway side structures, and reinforce the roadway sides and roof. Numerical simulation and field application results show that the support scheme can effectively realize safe control of the composite roof in coal roadways.
\end{abstract}

\section{Introduction}

With the depletion of coal resources in shallow parts of China, coal mining has gradually extended deeper, the mining environment has become increasingly complex, and the maintenance cost of roadways remains high [1]. The composite roof of a coal mine is composed of rock from different lithologies. There is a parting face between the rock and its fracture and caving (weak rock with coal streaks or thin seams easily produces subsidence displacement) $[2,3]$. The control of surrounding rock in compound roofs of loose and weak coal lanes has become one of the outstanding problems that affect safe and efficient mining in deep coal mines. Researchers have provided in-depth discussions and research on this issue [4-7]. Gong et al. studied the deformation and failure characteristics of the surrounding rock of deep high-stress roadways [8-11]. To study the phenomenon of large subsidence of the composite roof and the failure of support, Yu et al. summarized the failure forms under different surrounding rock conditions and analyzed the roadway instability mechanism of the composite roof [12]. Liu et al. studied the influence of factors, including the lithological characteristics of the roof surrounding rock, roadway section size, rock stress, stratification thickness, and weak intercalation, on the deformation and instability of the composite roof. They found that the ground stress, size of the 
rectangular roadway section, and thickness of each layer of the composite roof are the three main factors that control its deformation and instability [13]. Chang analyzed the deformation and failure characteristics of the surrounding rock of a mining roadway with a large cross section composite roof in a deep well. They believed that the roof of each layer is prone to separation due to the high ground stress and dynamic mining pressure, where the deformation of the two sides of the roadway affects the roof stability [14]. Zuo et al. studied the failure mode of anchor solids by using a combination of pull-out test and numerical simulation $[15,16]$. Zhu et al. used numerical simulations to study the roof failure mechanism of large-span roadways and found that the failure of the anchoring section was the main cause of roof deformation and failure [17]. Chen et al. studied the deformation of the roof surrounding rock and the support structure of the heavily stressed weak-rock roadway [18]. They believed that the anchoring-combined support technology can improve the strength of the roof surrounding rock and the bearing capacity of the supporting structure. Yang et al. used UDEC simulation software to analyze the failure process of the surrounding rock of the roadway. They believe that the low support strength is the main reason for the large deformation of the surrounding rock of the roadway. For this reason, they proposed a "bolt-cable-meshshotcrete + shell" support method [19]. Wang et al. proposed a roadway surrounding rock support system consisting of filling wall, shotcrete, grouting cable, prestressed anchor cable, and U-shaped steel based on the characteristics of the discontinuity of the roadway surrounding rock failure [20]. Zhao et al. studied the failure characteristics of the surrounding rock in deep weak and broken roadways, the composite support method of "shotcreting + grouting anchor bolt + anchor bolt + grouting anchor cable + anchor cable" is proposed by the full-section layer-double arch synergy reinforcement technology [21]. Peng et al. in order to solve the problem of difficult surrounding rock fragmentation of large-section supporting roadway take the large-section roadway of Pingdingshan Coal Mine as an example, through comparative analysis of various supporting schemes, put forward the "U-type steel + inverted arch + pouring concrete + backwall grouting" support method [22]. Tian and Gao analyzed the stress and displacement characteristics of the surrounding rock of a loose and weak deep well dynamic pressure roadway and established a loose and weak deep well dynamic pressure roadway support model with "multitruss anchor cables" as the main body [23]. Yan et al. constructed a thick coal seam roadway mechanics model, proposed a roadway support method with "truss anchor cable" as the core, and auxiliary bolts and cables, and simulated both supported and unsupported conditions [24]. Yu and Liu studied the impact of excavation disturbance on the surrounding rock of the roadway and put forward a targeted support for the surrounding rock of the roadway with "bolt, metal mesh, grouting, combined anchor cable and large diameter anchor cable" method [25].

The above studies focused on the deformation mechanism and supporting methods of the surrounding rock in deep loose soft coal roadways while also describing the difficulty of supporting such roadways. However, due to the existing conditions of each coal mine roadway and the complexity and uncertainty of the influencing factors, the deformation and failure mechanism and the adoption of roadway surrounding rock support technologies are distinct. Therefore, this article takes the 333 return airway of the Gaokeng Coal Mine as the research object, analyzes the deformation characteristics of the surrounding rock for the composite roof from a loose and weak coal roadway, describes the reasons for the large deformation, and studies the superiority of the prestressed truss anchor cable compared with the ordinary anchor cable. In addition, the comprehensive control technology of the prestressed truss anchor cable is proposed as the main body and the bolt + anchor cable + metal mesh as the auxiliary to ensure the safe use of the 333 return airway in the Gaokeng Coal Mine.

\section{Deformation Characteristics of Surrounding Rock}

2.1. Structural and Mechanical Characteristics. The Gaokeng Coal Mine is located in Pingxiang City, Jiangxi Province, China, as shown in Figure 1. The 333 return airway of Jiangxi Gaokeng Coal Mine is arranged along the seam floor with a total length of $90 \mathrm{~m}$ and a trapezoid design section shape (basal area is $5.63 \mathrm{~m}^{2}$ ), as shown in Figure 2. This roadway adopts the combined support method of bolt + anchor cable + I-steel ladder shed for support, while the roof is supported by five bolts, three anchor cables, and an I-steel ladder shed. The bolt specification is $\Phi 22 \mathrm{~mm} \times 2400 \mathrm{~m}$, and the row spacing between bolts is $600 \mathrm{~mm} \times 800 \mathrm{~mm}$ while the anchor cable specification is $\Phi 17.8 \mathrm{~mm} \times 5.0 \mathrm{~m}$, and the row spacing between bolts is $900 \mathrm{~mm} \times 800 \mathrm{~mm}$. The two sides are supported by five bolts and I-steel ladder sheds. The bolt specification is $\Phi 22 \mathrm{~mm} \times 2400 \mathrm{~mm}$, and the row spacing between them is $600 \mathrm{~mm} \times 800 \mathrm{~mm}$, as shown in Figure 3 . Investigations and analyses of the 333 return airway in the Gaokeng Coal Mine have determined the lithological characteristics of the surrounding rock of coal roof and floor, as given in Table 1.

By analyzing the conditions of the coal seam roof and floor, it is found that the composite roof rock layer has the following structural characteristics:

(1) The 333 return airway coal seam composite roof is thick and has a relatively small mechanical strength. The thickness of the coal seam is $5 \mathrm{~m}$ on average, and the thickness of the composite roof rock layer above the coal seam is as high as $4.5 \mathrm{~m}$, which is composed primarily of siltstone, shale, mudstone, coal, and other low-strength rock bodies.

(2) There are many layers and $0-100 \mathrm{~mm}$ coal lines in the composite roof. The presence of small layers weakens its bearing capacity and leads to a reduced adhesion between rock layers, uneven roof deformation, and sinking.

(3) The composite roof rock layer is thick, the structure is weak and loose, and there are many small layers. Thus, the effective length of the anchor cable cannot 


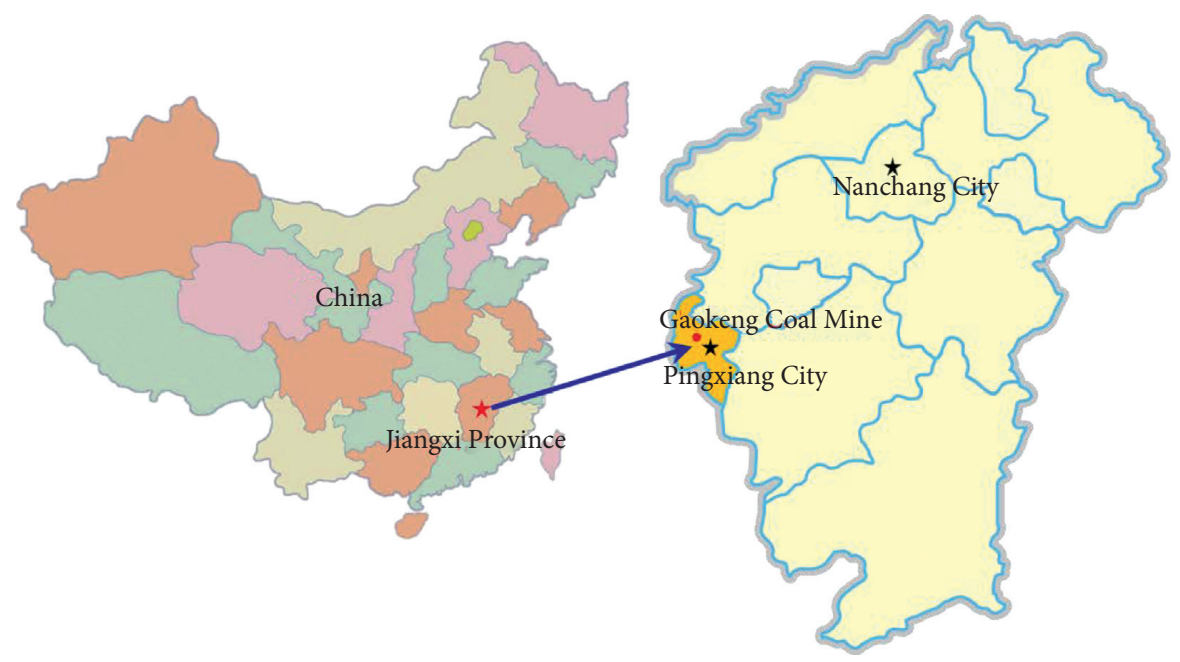

Figure 1: Geographical location of the Gaokeng Coal Mine.

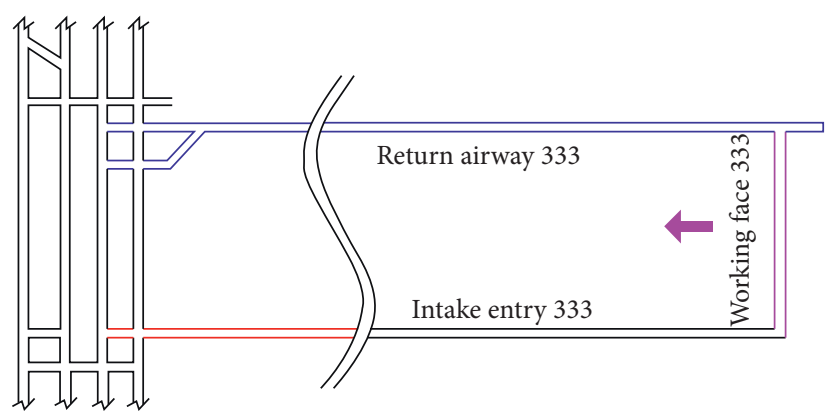

Figure 2: The schematic of the 333 return airway.

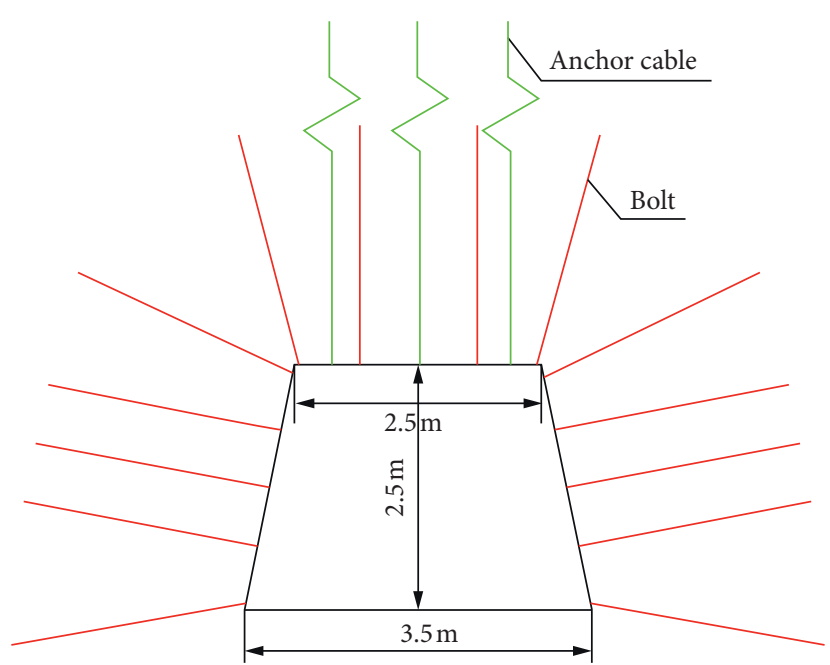

FIgURE 3: Original support scheme for a coal roadway.

TABLE 1: Coal seam roof and floor properties.

\begin{tabular}{lccc}
\hline Roof and floor type & Rock type & Thickness $(\mathrm{m})$ & Lithologic features \\
\hline Pseudotop & Shale, coal & $0-1.0$ & Gray-black, thin layer, coal line \\
Direct top & Shale & 1.5 & Black dense shale \\
Main roof & Siltstone & 10.0 & Black thin mudstone with thin-layer siltstone \\
Main floor & Fine sandstone & 8.0 & Dark gray fine sandstone, thin layer of mudstone black carbonized smooth surface \\
\hline
\end{tabular}


be inserted into the stable rock layer with a high bearing strength, and it cannot fully exert its suspension function, which serves only as a composite beam.

\subsection{Deformation Characteristics}

2.2.1. Surrounding Rock of the Roadway Has a Large Deformation, and the Roof Sinks Heavily Overall. The composite roof has a large thickness with many small layers, the structure is loose, and the bearing capacity is poor and coupled with the influence of mining and other stresses. The lower part of the composite roof cannot withstand the pressures from the upper rock layer, which aggravates its destruction process. This causes uneven subsidence and delamination in each rock layer and can even cause local roof fall accidents.

The main function of the anchor cable is to suspend the low-strength composite rock layer in the stable rock layer. Most of the bearing capacity in the supporting system needs to be supported by the anchor cable; however, the strength of the anchor cable is too high. When the anchor cable reaches a certain length (more than $10 \mathrm{~m}$ here), the construction requirements are too strict. Judging from the on-site construction of the Gaokeng Coal Mine, after supporting the composite roof with the anchor cable, the deformation rate of the roof is reduced. However, the roof still sinks, the anchor cable sinks with the roof, and the roadway sides bulge outwards.

2.2.2. Long Deformation Duration. The compound loose and weak roof in Gaokeng Coal Mine not only has a large amount of sinking and a fast deformation speed but also has a long deformation duration, which can last for two years or longer. Ever since the excavation of the 333 return airway, the surrounding rock of the roadway has been in an unstable state. Thus, it is necessary to continuously maintain the normal use of the roadway section by expanding the roadway.

\section{Deformation Mechanism of Surrounding Rock of Compound Roof}

The Gaokeng Coal Mine contains multiple faults, such as F3. The structural stress is abnormally strong, which results in large deformations in the surrounding rock of the roadway. The overall roof sinking is significant, the strength of the coal and rock body itself is low, and the structure is loose, which is accompanied by geological disasters such as spalling and cracking:

(1) The composite roof of the loose and weak coal roadway has a greater thickness, worse bearing capacity, and lower mechanical strength. Even if the supporting density is increased, the problem of roof sinking is not solved. This is mainly because the composite roof is too thick and contains several small layers. The effective anchorage length of the anchor cable is contained in the composite roof, and the anchoring end cannot penetrate the stable rock layer with a strong bearing capacity. The loss of balance in the roadway support system leads to support failure. At this time, the anchor cable fails to suspend and stretch the composite roof and serves only to connect several-layer rock bodies inside the composite roof to enhance its bending resistance in the anchoring area. As shown in Figure 4, the vertical deformation of the anchor end (point $A$ ) and head (point $B$ ) is synchronized. That is, the anchor cable sinks synchronously with the roof plate, and the anchor cable cannot play its intended role. With some stretching, the pressure of the overlying strata is borne almost entirely by the roof.

(2) On the one hand, the mechanical strength of the two coal bodies in the 333 return airway is low, the structure is weak and loose, and the roadway has been expanded repeatedly. Therefore, the rupture zone range has continued to expand, and the anchoring force of the bolt has continued to weaken. On the other hand, the stress during roof sinking has continuously transferred to the two sides of the roadway, which aggravates the destruction process of the two coal body sides and the range of the fracture zone increases, which results in an increased internal displacement of the two sides. The effects of these aspects cause the rupture zone of the two coal bodies to far exceed the length of the bolt body. Therefore, the anchoring section is entirely in the loose rupture zone coal body, and the support completely fails. Similarly, the horizontal deformations of the anchor end (point $C$ ) and head (point $D$ ) of the bolt are synchronized, and the bolt does not exert its proper tensile effect.

(3) The floor is the weakest part of the roadway surrounding rock control. As no effective support measures were taken for the floor at the site, the pressure of the roadway sides is transmitted to the surrounding rock of the floor, which is squeezed by the horizontal in situ stress, tectonic stress, and upward pressure of the lower rock layer. The concentration of stress is therefore enhanced, which results in heaving at the bottom of the floor.

Establishing an active support system that implements a wider range of control for the surrounding rock of the coal roadway can provide highly reliable anchoring points. This effectively improves the stress state of the surrounding rock, improves its overall bearing capacity, and ensures its stability. This is the key to solving the existing support problem and situations like it.

\section{Composite Roof Support Principle and Theoretical Analysis of Truss Anchor Cable}

4.1. Support Principle. The sinking of the composite coal roof is accompanied with a release and transfer of the surrounding rock stress. Specifically, the roof pressure is 


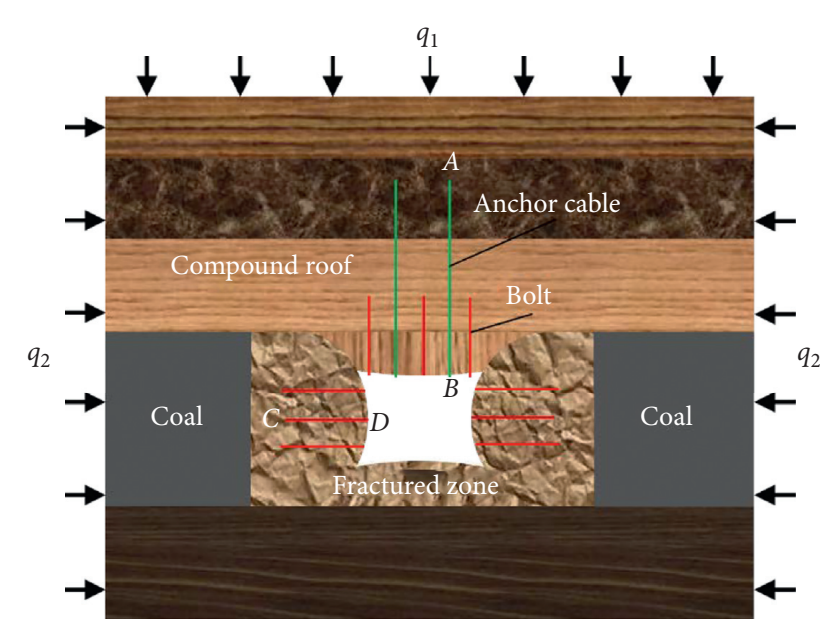

FIgURE 4: Features of the coal roadway support.

transferred to the coal bodies of the two roadways and leads to stress concentration, which intensifies the coal body rupture process. At the same time, the extensive rupture of the coal bodies and the continuous inward movement into the roadway space cause the support capacity of the roadway sides to rapidly weaken, causing the roof to further bend and sink. This cycle continuously repeats and is one of the main reasons for the large deformation of the surrounding rock of the composite roof in the loose and weak coal roadway. Therefore, the support of the surrounding rock of the composite roof should not ignore the support effects of the two coal bodies. The roof, roadway sides, and floor should be regarded as a single entity to achieve the support effect of a solid and strong roof.

To prevent sinking and delamination of the composite roof in the coal roadway and realize its normal use requirements, it is necessary to first improve the roof support force. To this end, the following three aspects should be considered. (1) Support the roof directly to improve the stress state of the surrounding rock, improve the strength and integrity of the surrounding rock, and enhance its bearing capacity. (2) The roadway sides play an important role in the roof, which needs to be strengthened to improve the integrity of the surrounding rock of the coal body, reduce the range of the fracture zone, and strengthen the two coal roadway sides. The support capacity helps avoid the occurrence of geological disasters, such as rib spalling and cracking. (3) The anchoring section of the anchor cable must go deeper into the rock layer to find a strong bearing capacity and prevent the anchoring section from escaping the surrounding rock and failing.

The above analysis indicates a comprehensive control method with prestressed truss anchor cable as the core is helpful for the deformation mechanism and characteristics of the composite roof that surrounds the loose and weak coal roadway, as shown in Figure 5. (1) The prestressed truss anchor cable can be extended to the four-pointed, deep, three-way compressive stable rock mass as the anchor point and basis of the bearing structure. The anchor point should not be easily affected by the separation and deformation of

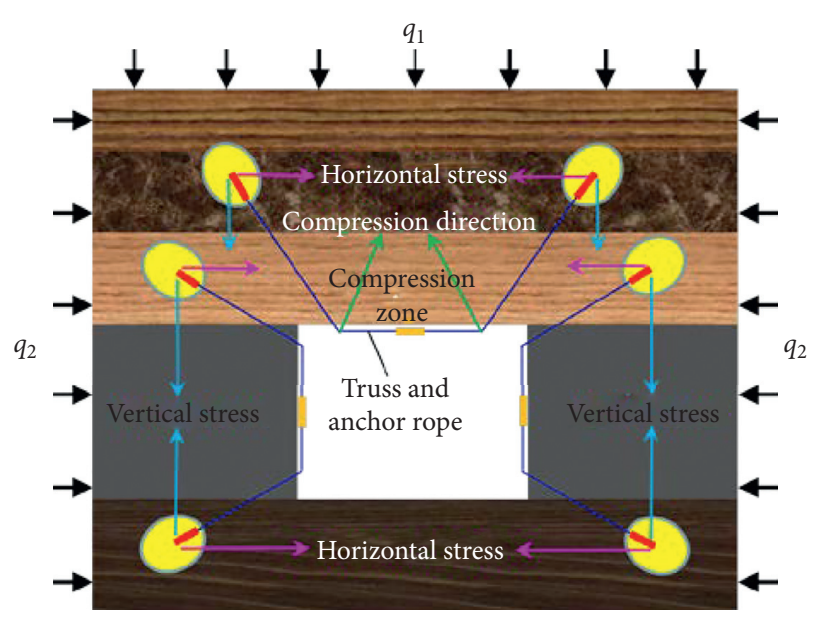

Figure 5: The principle of the prestressed truss anchor cable support.

the rock body to ensure that the supporting structure is fully exerted. This fulfills the support goal of having a solid support and strong roof. (2) The common anchor cable is in point contact with the surrounding rock of the roadway free surface, which readily causes the stress concentration to rupture the shallow surrounding rock. The truss cable is in contact with the surrounding rock surface of the roadway to form a continuous compressive stress zone, which reduces the degree of stress concentration. (3) The prestressed truss anchor cable is an active supporting structure that simultaneously provides horizontal and vertical compressive stress in the roof or the surrounding rock. This overcomes the defect where the ordinary anchor cable support cannot provide a horizontal support force, which improves the anchorage area. The stress state of the surrounding rock and the neutral axis position of the anchor zone move outward, which strengthens the mechanical properties of the rock mass in the anchor zone and improves its resistance to deformation. This improves the integrity of the rock surrounding the roadway.

4.2. Stress Analysis of Truss Anchor Cable. The superiority of the prestressed truss anchor cable is mainly reflected in the improvement of the surrounding rock stress state and effective support range. The composite roof after support can be regarded as a composite beam [26], as shown in Figure 6. The pressure of the surrounding rock mass on the anchor cable is related primarily to factors such as the in situ stress, tectonic stress, mining, mechanical properties of coal and rock mass, and the rock layer thickness. Assuming that $q(x)$ is evenly distributed and $g(x)$ is linearly distributed, $g(0)=k_{1} \gamma h$ at the anchoring section of the anchor cable, and $g(l \cos a)=k_{2} \gamma h$ at the anchoring head position, where $l$ is the effective anchoring length. When the prestressed truss anchor cable is in force balance, the resultant forces in the vertical and horizontal directions are zero, and the prestress $F_{0}$ of the anchor cable and the prestress $F_{1}$ of the truss are obtained from the following two balance equations: 


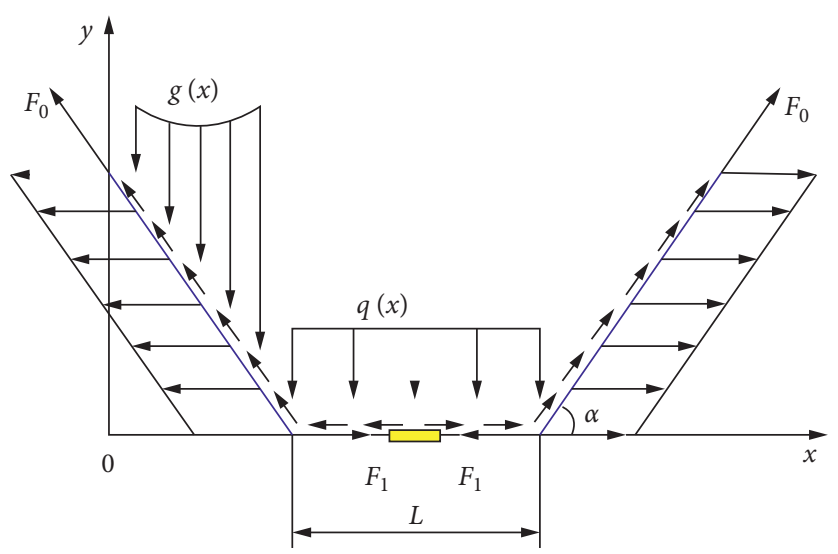

FIGURE 6: Stress model of the truss anchor cable.

$$
\begin{aligned}
& F_{0}=-\frac{b \cos a\left(k_{1}+k_{2}\right)\left[f_{1}(1+\lambda \tan a) \sin a+1\right]+L}{2 \sin a} \gamma h, \\
& F_{1}=-\frac{b \cos a\left(k_{1}+k_{2}\right)(\cos a+\lambda)+L(\cos a+f)_{2}}{2} \gamma h .
\end{aligned}
$$

where $h$ is roadway buried depth $(\mathrm{m}) ; b$ is roadway width $(\mathrm{m}) ; \gamma$ is roadway roof covering weight $\left(\mathrm{kN} / \mathrm{m}^{3}\right) ; f_{1}$ is frictional force between the inclined part of the truss anchor cable and the rock mass $(\mathrm{kN} / \mathrm{m}) ; f_{2}$ is frictional force between the horizontal part of the truss anchor cable and the rock mass $(\mathrm{kN} / \mathrm{m})$; $a$ is the inclination angle of the anchor cable borehole $\left({ }^{\circ}\right) ; L$ is the length of truss $(\mathrm{m}) ; \lambda$ is the coefficient of lateral compression; and $k_{1}, k_{2}$ are slope.

Through the analysis of the above mechanical model, ordinary anchor cables only apply a prestress to the inside of the rock mass through the tray, while the compressive stress has a limited range of influence and is suitable to only strengthen the support in local areas of the surrounding rock. The truss and anchor rope are prestressed at the connector, which easily forms a locked structure. Thus, the supporting structure does not easily fail, which effectively prevents the overall roof sinking and the occurrence of roof fall accidents.

The neutral axis theory in material mechanics gives the neutral axis of the composite beams after the truss and anchor rope are anchored, as shown in equation (2). The computational mechanical model of the neutral axis of the anchoring zone is as shown in Figure 7.

$$
\sigma=\frac{M_{z} y}{I_{z}}-\frac{F_{1}}{A}=0 .
$$

According to equation (2),

$$
y=\frac{F_{1} I_{z}}{M_{z}}
$$

where $A$ is cross-sectional area of the anchor cable $\left(\mathrm{m}^{2}\right) ; I_{\mathrm{z}}$ is the moment of inertia of the rock layer in the composite beam $\left(\mathrm{m} \cdot \mathrm{kg} \cdot \mathrm{s}^{2}\right)$; and $M_{\mathrm{z}}$ is the bending moment of the rock layer in the composite beam $(\mathrm{N} \cdot \mathrm{m})$.
Integrating bending theory of the combined beam with equation (2), the tensile stress on the surrounding rock in the area of the truss anchor cable is given as

$$
\sigma_{t}=\frac{M_{h}\left(h_{x}-y\right)}{I_{y}}-\frac{F_{1}}{A}=\frac{M_{h} h_{x}}{I_{y}}-\frac{M_{h} F_{1} I_{z}}{M_{z} I_{y}}-\frac{F_{1}}{A},
$$

where $y<h_{x}<h / 2$. According to the definition of the calculation model bending moment,

$$
M_{h}=M-M_{h y}<M
$$

From comparisons of equations (4) and (5), we find that

$$
\sigma_{t}<\frac{M_{h} h_{x}}{I_{y}}<\frac{M h_{x}}{I_{y}}
$$

where $M_{h}$ is the bending moment when supported by the truss anchor cable $(\mathrm{N} \cdot \mathrm{m}) ; M_{h y}$ is the bending moment formed by the prestress of the truss anchor cable $(\mathrm{N} \cdot \mathrm{m}) ; h_{x}$ is the vertical distance from the calculated point to the abscissa (m); $M$ is the bending moment when using an ordinary anchor cable support $(\mathrm{N} \cdot \mathrm{m}) ; I_{y}$ is the moment of inertia for the internal rock layer when using the truss anchor cable for support $\left(\mathrm{m} \cdot \mathrm{kg} \cdot \mathrm{s}^{2}\right)$; and $M_{y}$ is the bending moment of the internal rock layer when using the truss anchor cable for support torque $(\mathrm{N} \cdot \mathrm{m})$.

From this analysis, the prestressed truss anchor cable is adopted as the core support technology, and the neutral axis of the surrounding rock in the anchorage area is lower than that using ordinary anchor cables $\left(F_{1} I_{z}\right) / M_{z}$. At the same time, the neutral axis of the surrounding rock in the anchorage area is related to the prestress of the truss anchor cable. A greater prestress brings the neutral axis closer to the surrounding surface of the surrounding rock, which is more conducive to improve the stress state of the surrounding rock.

\section{Engineering Test}

5.1. Support Plan. According to the deformation and failure characteristics of the surrounding rock of the 333 return airway and the analysis of the composite roof support, the prestressed truss anchor cable is used as the main body, and 


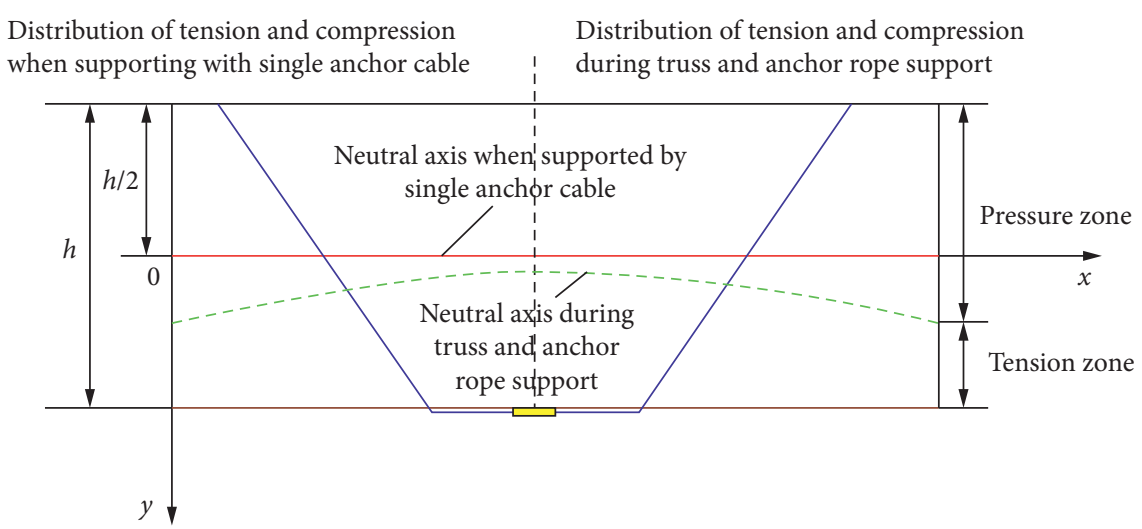

Figure 7: Computational mechanics model of the neutral axis in the anchorage zone [27].

the comprehensive control technology with bolt + anchor cable + metal mesh is the auxiliary. The numerical simulation and field support test along with the specific support scheme is shown in Figure 8.

Bolts and metal meshes are the initial support structures when unloading the surrounding rock of the roadway, which allows certain deformations. The secondary support is the prestressed truss and anchor rope along with the anchor cables, which are used primarily to support the surrounding rock of the roadway during the creep period, improve the overall strength of the broken surrounding rock, and achieve permanent stability of the roadway $[28,29]$.

The parameters of the 333 return airway bolt and metal mesh support are as follows:

(1) The roof of the roadway is supported by 4 lefthanded, threaded, steel bolts without longitudinal reinforcement along with $2.4 \mathrm{~m}$ ladder beams and a metal mesh. The specification of the bolts is $\Phi 22 \mathrm{~mm} \times 2400 \mathrm{~mm}$, the spacing between the bolts is $750 \mathrm{~mm} \times 800 \mathrm{~mm}$, and the anchors have a force that is not less than $70 \mathrm{kN}$. The corner anchors should be installed at an inclined angle of $15^{\circ}$ outwards. The other anchors are arranged perpendicular to the roof direction using an elongated anchoring method. Each anchor is attached by two sections of Z2550 medium-speed resin drug rolls, as shown in Figure 9. The metal mesh is $\Phi 6 \mathrm{~mm}$ with a $100 \mathrm{~mm} \times 100 \mathrm{~mm}$ grid.

(2) The roadway side is supported by 4 left-handed, threaded, steel bolts without longitudinal ribs along with $2.5 \mathrm{~m}$ ladder beams and a metal mesh. The specification of the bolts is $\Phi 22 \mathrm{~mm} \times 2400 \mathrm{~mm}$, and the anchoring force is not less than $70 \mathrm{kN}$. The bottom angle bolt should be installed downward at $9^{\circ}$, and the shoulder angle bolt should be installed downward at $31^{\circ}$. Two sections of the Z2550 medium-speed resin cartridges are lengthened and anchored. The metal mesh is $\Phi 6 \mathrm{~mm}$ with a $100 \mathrm{~mm} \times 100 \mathrm{~mm}$ grid. The bolts must be provided at the stubble of the metal mesh and be close to the rock face, while the length of the stubble between meshes should not be less than $100 \mathrm{~mm}$.
The surrounding rock anchor cable support adopts two different types of anchor cables (top ordinary anchor cable and full-section truss and anchor rope) based on the deformation and failure characteristics of the 333 return airway and the geological conditions and degree of mining.

5.1.1. Roof Anchor Cable. The middle of the roadway roof is supported with one anchor cable at $\Phi 17.8 \mathrm{~mm} \times 7.0 \mathrm{~m}$ and a row distance of $800 \mathrm{~mm}$, which is arranged between two rows of bolts. The anchor cable uses five rolls of Z2840 resin drug rolls, and the anchoring force is not less than $100 \mathrm{kN}$. The anchor cable tray adopts a compressible square shim device, whose specification is $350 \mathrm{~mm} \times 350 \mathrm{~mm} \times 10 \mathrm{~mm}$.

\subsubsection{Truss and Anchor Rope}

(1) Roof. A truss and anchor rope system is arranged every two rows of bolts on the roof, and the specification of the steel strands (nine strands) is $\Phi 17.8 \mathrm{~mm} \times 7.0 \mathrm{~mm}$. The spacing between anchor cables is $2000 \mathrm{~mm} \times 1600 \mathrm{~mm}$, while the anchoring force is not less than $140 \mathrm{kN}$ and the preload is not less than $70 \mathrm{kN}$.

(2) Roadway Sides. A truss and anchor rope system is arranged every two rows of bolts in the roadway sides. The specifications of the steel strands (nine strands) is $\Phi$ $17.8 \mathrm{~mm} \times 6.0 \mathrm{~mm}$, and the spacing between the anchor cables is $2000 \mathrm{~mm} \times 1600 \mathrm{~mm}$. The anchoring force is not less than $140 \mathrm{kN}$ and the preload is not less than $70 \mathrm{kN}$.

The angle of the anchor cable is installed based on the design. Every two anchor cables in the upper part are connected as a group and with a $2.0 \mathrm{~m}$ truss to form a single unit to reduce further deformations of the loose surrounding rock, as shown in Figure 10.

5.2. Numerical Simulations. The FLAC3D numerical simulation software was used to analyze the 333 return airway using the original support plan and the prestressed truss and anchor rope as the main body, and the bolt+anchor cable + metal mesh as the auxiliary comprehensive support plan. The calculation model is shown in Figure 11. The 


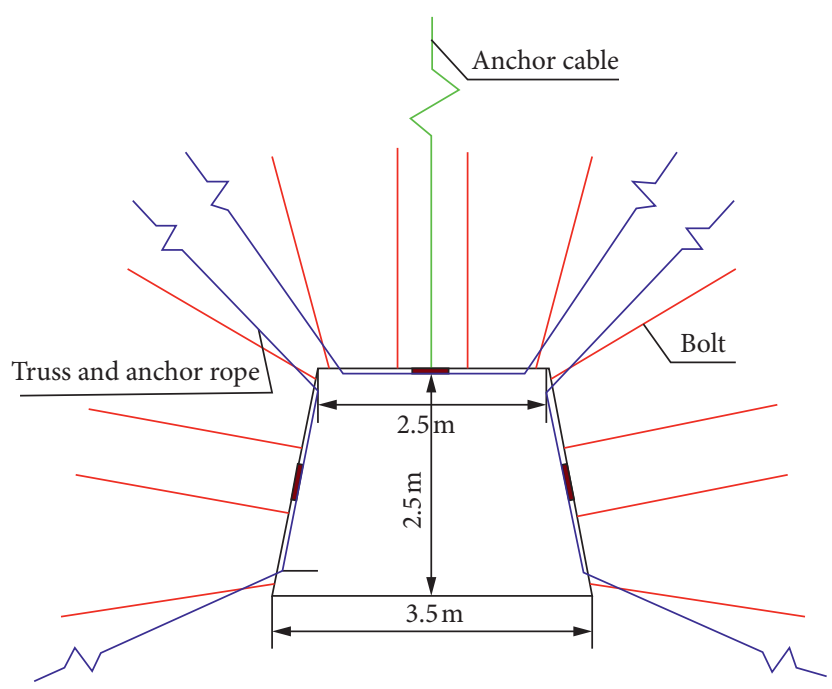

Figure 8: Roadway support scheme.

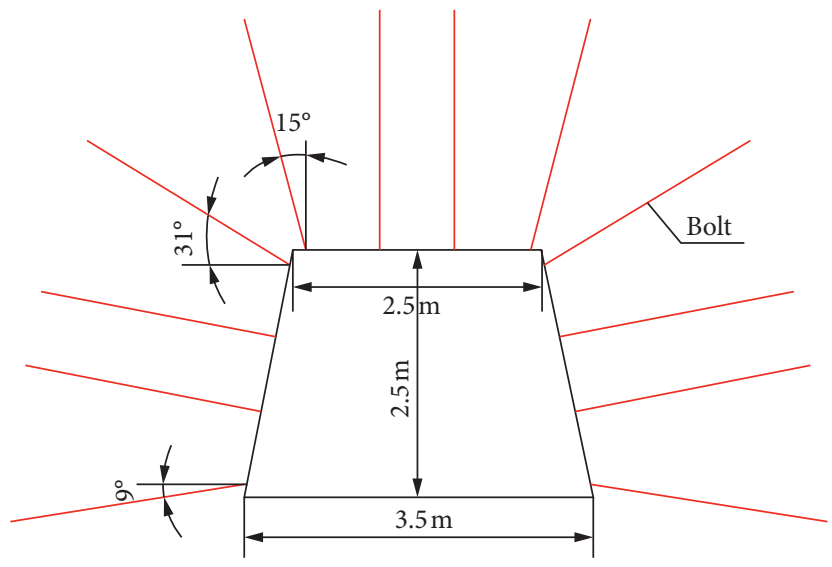

Figure 9: Cross section of the bolt support.

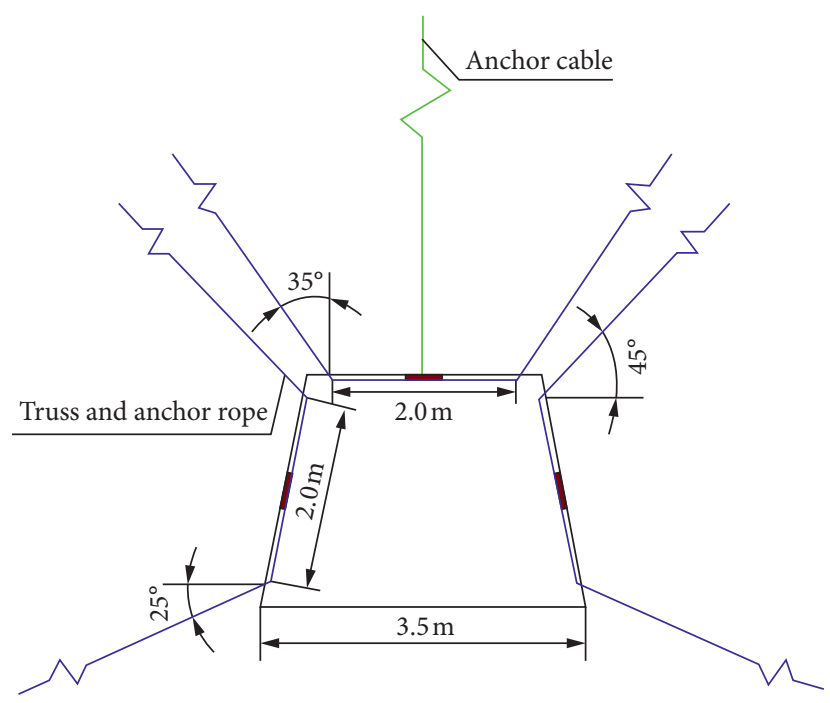

Figure 10: Cross section of anchor cable with the truss and anchor rope support. 


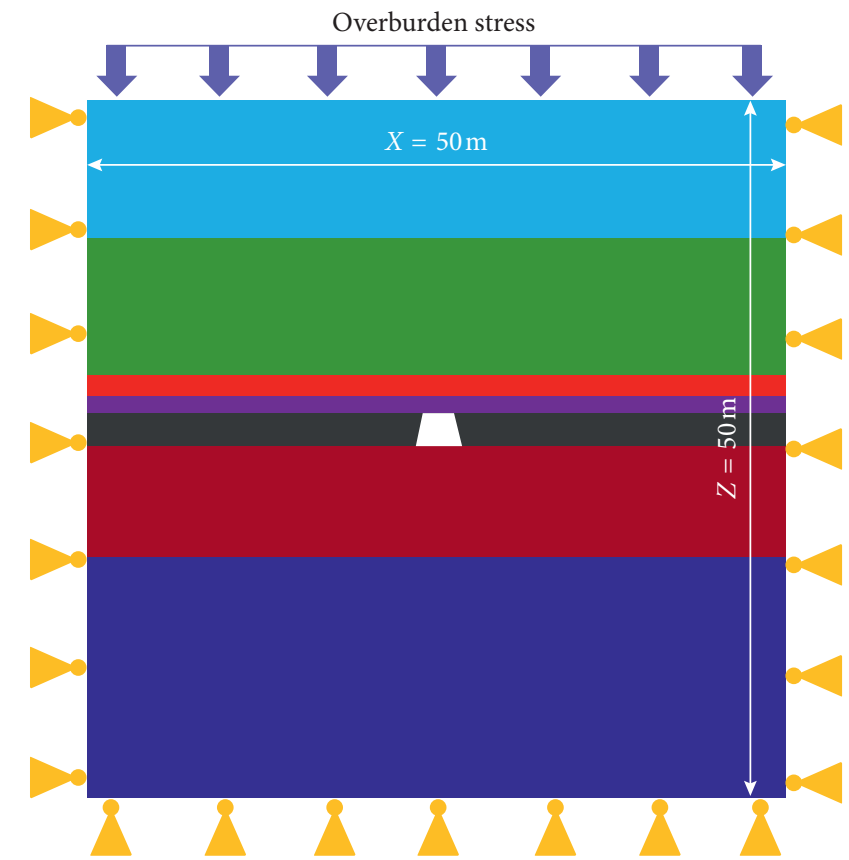

Figure 11: Three-dimensional numerical model of the 333 air roadway.

height $\times$ length $\times$ thickness of the calculation model is $50 \mathrm{~m} \times 50 \mathrm{~m} \times 50 \mathrm{~m}$. Displacement constraints are imposed on the left and right boundaries, the front and rear boundaries, and the lower boundaries. The vertical stress is taken from the weight stress, and an equivalent load of $20 \mathrm{MPa}$ is applied to the upper boundary. The calculation model adopts the Mohr-Coulomb yield criterion and calculates the initial ground stress field balance from $\sigma_{z z}=20 \mathrm{MPa}, \sigma_{x x}=24 \mathrm{MPa}$, and $\sigma_{y y}=21 \mathrm{MPa}$, which then calculates the roadway excavation after the balance. The calculated mechanical parameters are shown in Table 2.

The distribution of the plastic zone of the rock surrounding the roadway under the original (new) support scheme is shown in Figure 12 (Figure 13). In the original support scheme, the plastic zone depth of the roadway wall and roof surrounding rock is relatively large at approximately $2.0 \mathrm{~m}$, and the plastic zone of the floor is relatively small at $1.0 \mathrm{~m}$. After adopting the new support scheme, the depth of the plastic zone of the surrounding rock for the roadway is significantly improved. The depth of the roadway section and the roof plastic zone is approximately $0.5 \mathrm{~m}$, which is $1.5 \mathrm{~m}$ less than that of the original support scheme of $2.0 \mathrm{~m}$. This indicates that the new support scheme can effectively control the depth of the plastic zone. The anchoring foundation of the bolt (cable) is located outside the plastic zone, which benefits the stability control of the surrounding rock for the roadway.

A cloud map of the surrounding rock displacement of the roadway under the original and new support scheme is shown in Figures 14 and 15. Under the original support scheme, the deformation of the roof is relatively large with a subsidence as high as $0.65 \mathrm{~m}$ and a deformation that reaches $0.5 \mathrm{~m}$. After adopting the new supporting scheme, the displacement cloud image is significantly improved, the roof subsidence is reduced to $0.049 \mathrm{~m}$, and the roadway sides are reduced to $0.04 \mathrm{~m}$, indicating that the new supporting scheme can effectively control the deformation of the roadway surrounding rock.

5.3. Engineering Effect Inspection. The effects of the support scheme were monitored for up to 90 days, and the deformation of the 333 return airway is shown in Figure 16. After monitoring, the total convergence of the coal roadway roof and floor after using the new support scheme is $363 \mathrm{~mm}$, and the total convergence of the roadway sides is $253 \mathrm{~mm}$. Thus, the deformation of the surrounding rock for the roadway is effectively controlled, and the failure of the bolt and the roof collapse did not meet the use requirements during roadway service.

\section{Discussion}

The composite roof of a coal mine easily separates from the layers, and the bed-separation volume and sinkage increase with the rupture range of the two sides. Therefore, the advantages of the combined support technology for the prestressed truss and anchor rope and bolts for the composite roof of coal mines are as follows. (1) Timely support and high prestress control for the separation of the composite roof to maintain its integrity and enhance its selfsupporting abilities, transform the composite roof from a load body to a carrier, and evenly transfer the load of the overlying strata to the roadway sides, which reduces their stress concentration. (2) High prestressed supports improve the bearing capacity of the two sides, reduce their rupture range for the roadway, and enhance their stability, which provides strong support to maintain the stability of the composite roof. (3) The compressive stress areas formed by 
TABLe 2: Numerical calculation parameters.

\begin{tabular}{lcccccc}
\hline $\begin{array}{l}\text { Rock } \\
\text { formation } \\
\text { name }\end{array}$ & $\begin{array}{c}\text { Bulk density } \\
\left(\mathrm{g} . \mathrm{cm}^{-3}\right)\end{array}$ & $\begin{array}{c}\text { Uniaxial compressive } \\
\text { strength }(\mathrm{MPa})\end{array}$ & $\begin{array}{c}\text { Uniaxial tensile } \\
\text { strength }(\mathrm{MPa})\end{array}$ & $\begin{array}{c}\text { Cohesion } \\
(\mathrm{MPa})\end{array}$ & $\begin{array}{c}\text { Internal } \\
\text { friction angle } \\
\left({ }^{\circ}\right)\end{array}$ & $\begin{array}{c}\text { Elastic } \\
\text { modulus } \\
(\mathrm{GPa})\end{array}$ \\
\hline Fine sandstone & 2650 & 37 & 3.15 & 6.5 & 30 & \multicolumn{1}{c}{$\begin{array}{c}\text { Poisson's ratio } \\
\text { Siltstone }\end{array}$} \\
Coal & 1400 & 32 & 2.81 & 3.7 & 36 & 28 \\
Shale & 1900 & 12 & 1.43 & 1.5 & 18 & 0.29 \\
\hline
\end{tabular}

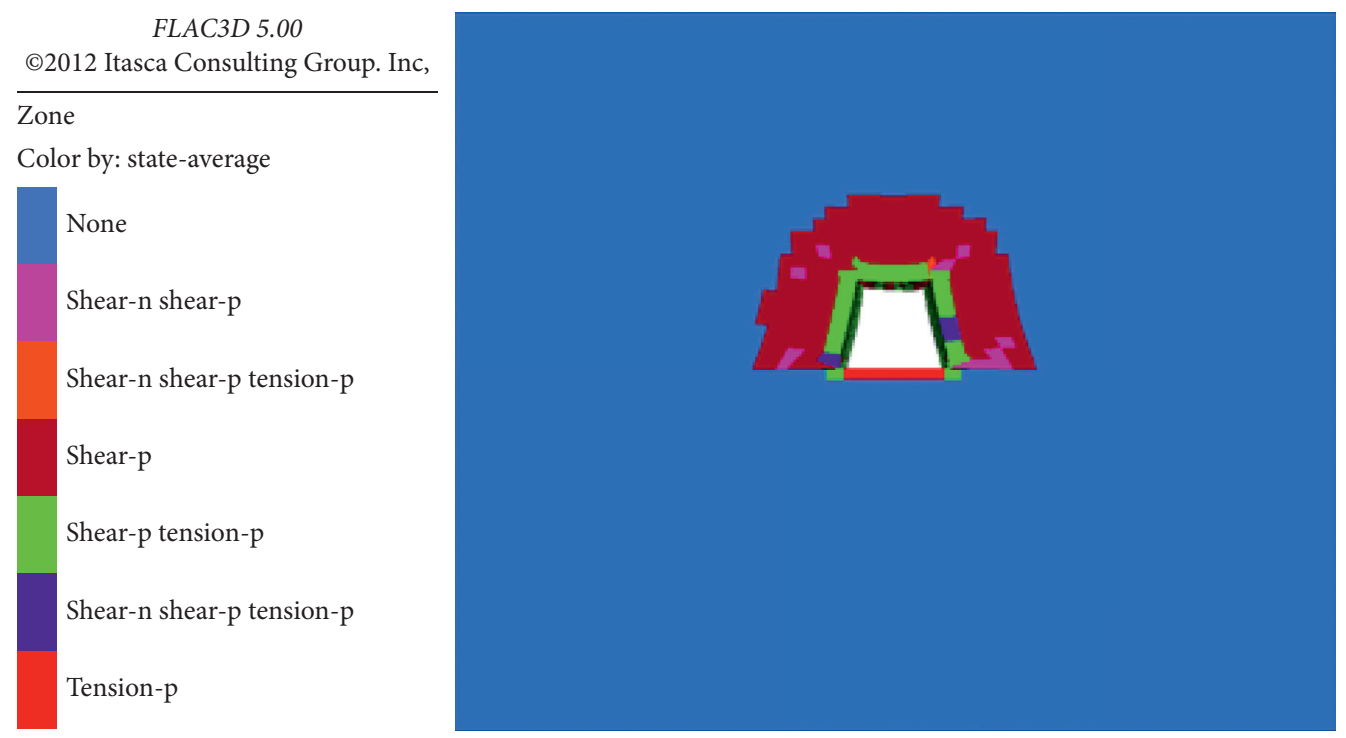

FIGURE 12: Distribution of the plastic zone in the surrounding rock of the original support technology.

FLAC3D 5.00

(C)2012 Itasca Consulting Group. Inc,

Zone

Color by: state-average

None
Shear-n shear-p
Shear-n shear-p tension-p
Shear-p
Shear-p tension-p
Tension-p

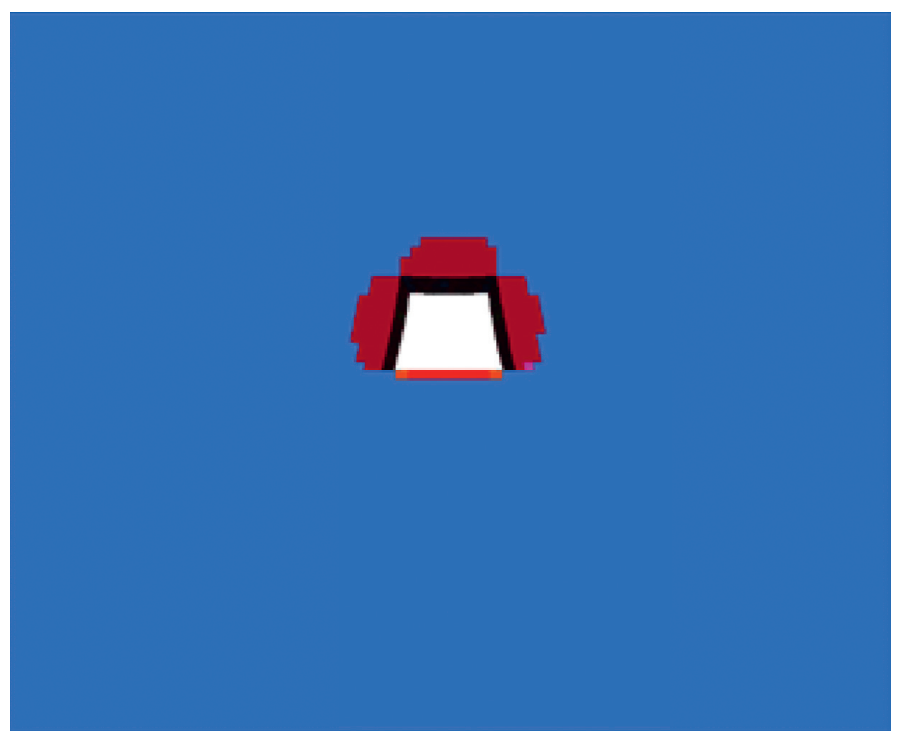

FIGURE 13: Distribution of plastic zone in the surrounding rock of the new support technology.

the truss and anchor rope and the bolt are coupled with each other to form a spatial prestressed network. This forms a continuous overall compressive stress area where the anchor cable prestress plays the role of the skeleton support and the bolt provides a supplementary addition for continuous bearing. The formation of the spatial stress network effectively guarantees the stability of the roof rock in the anchored area.

The control effects of the prestressed truss and anchor rope and bolts on the surrounding rock of the roadway are affected by factors such as the supporting structure and density, material, anchor agent, and row distance. At the 
FLAC3D 5.00

(02012 Itasca Consulting Group. Inc,

Contour of displacement

$6.4830 E-01$
$6.0000 E-01$
$5.5000 E-01$
$5.0000 E-01$
$4.5000 E-01$
$4.0000 E-01$
$3.5000 E-01$
$3.0000 E-01$
$2.5000 E-01$
$2.0000 E-01$
$1.5000 E-01$
$1.0000 E-01$
$5.0000 E-02$
$0.0000 E+00$

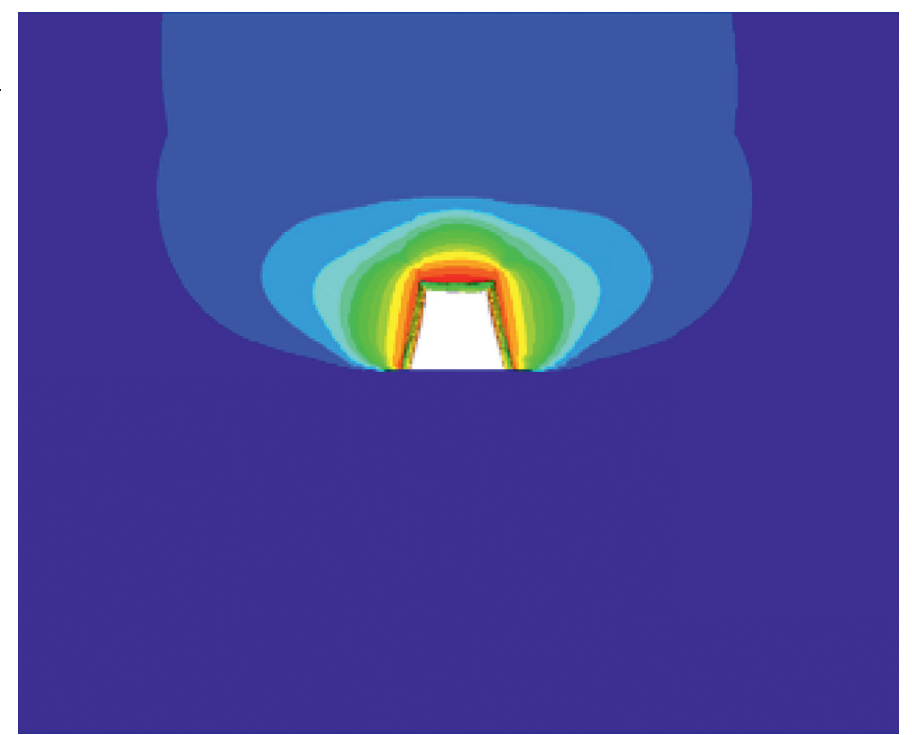

FIGURE 14: Cloud map of the roadway surrounding rock displacement under the original support scheme.

FLAC3D 5.00 (C)2012 Itasca Consulting Group. Inc,

Contour of displacement
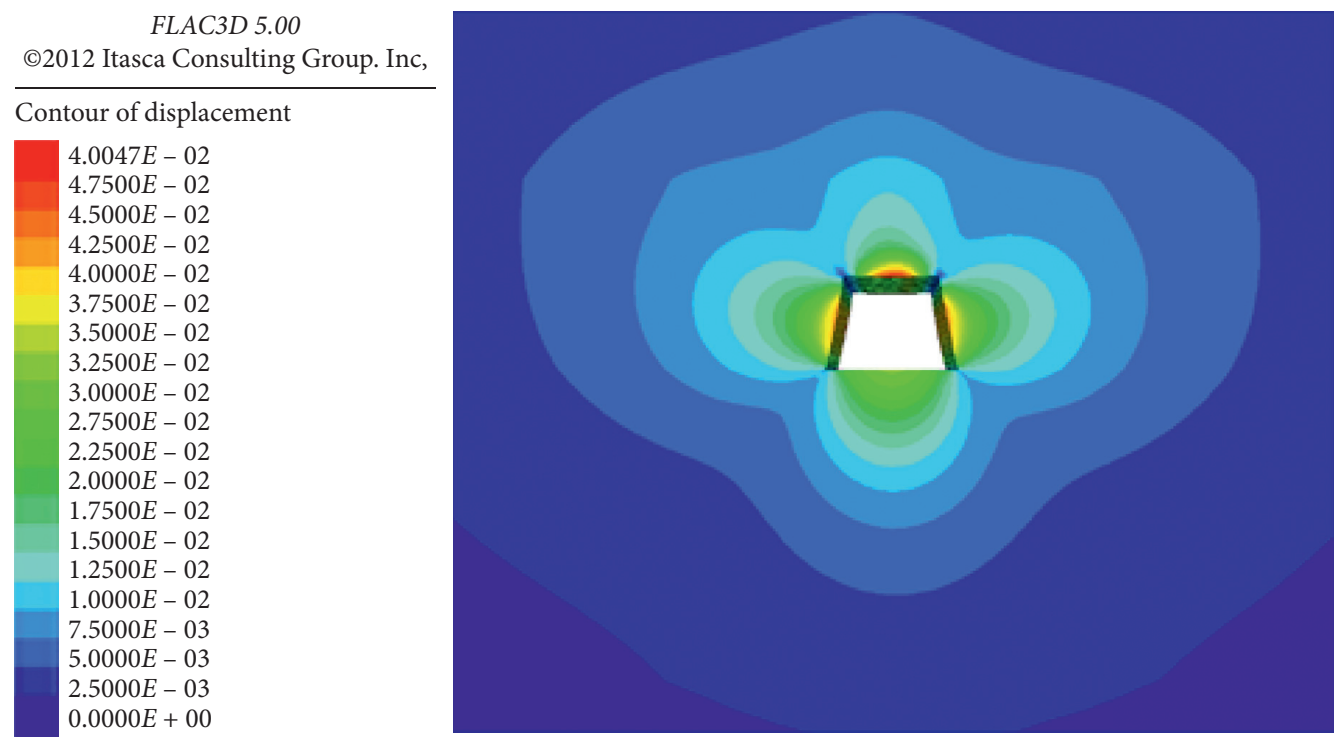

FIGURE 15: Cloud map of the roadway surrounding rock displacement under the new support scheme.

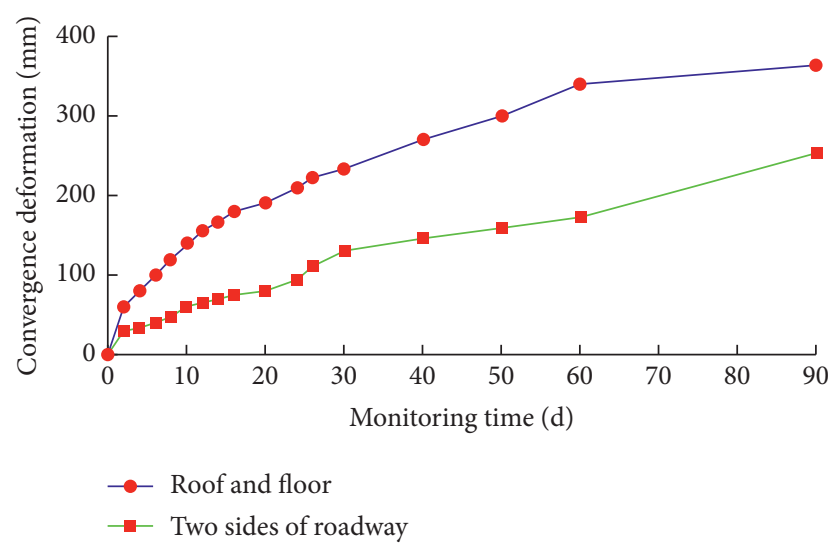

FIGURE 16: Roadway surrounding rock monitoring curve. 
same time, it is also affected by the surrounding rock factors such as its mechanical properties and structural characteristics, including its hardness coefficient, hydrological conditions, and structure. Effective control of the surrounding rock of the roadway can be better achieved only by scientifically and comprehensively considering various factors and restoring the actual project status.

\section{Conclusions}

(1) The coal body rupture is aggravated as the pressure of the composite coal roof shifts to the two sides of the roadway, which results in a rapid weakening of its support capacity. This causes the roof to further bend and sink, which forms a vicious cycle. To better support the composite roof in coal roadways, the roof, two roadway sides, and the floor should be regarded as a single unit to achieve the support effect of having solid roadway sides and a strong roof.

(2) The stress model of the truss and anchor rope was established, and the superiority of the prestressed truss anchor cable compared with the ordinary anchor cable was studied. The anchoring section of the truss-anchor cable is located in the stable deep rock layer at the four sharp corners of the roadway, which improves the stress state of the surrounding rock in the anchorage area and the resistance to deformation and failure of the coal and rock masses.

(3) The prestressed truss and anchor rope are proposed as the main body while the bolt + anchor cable+ metal mesh is proposed as the auxiliary comprehensive control technology. On-site support tests and numerical simulations show that while this technology improves the overall load-bearing capacity of the composite roof, it also strengthens the roadway side structure and plays a supporting role of reinforcing the roadway sides and roof to meet the service requirements during roadway service. The study can be extended to similar loose, weak, and large deformation roadways using the prestressed truss and anchor rope as the main support technology. This improves the stress state of the surrounding rock in the anchoring area, improves the integrity of the surrounding rock, and determines a reasonable support plan.

\section{Data Availability}

All the data generated or published during the study are included within the article; no other data were used to support this study.

\section{Conflicts of Interest}

The authors declare that they have no conflicts of interest regarding the publication of this paper.

\section{Acknowledgments}

This work was financially supported by the National Natural Science Foundation of China (Grant nos. 51804109, 51874130, 51974118, and 51774133); the Scientific Research Fund of Hunan Provincial Education Department (Grant no. 18C0333); the Scientific Research Foundation for Doctor of Hunan University of Science and Technology (Grant no. E51851); and the Graduate Research and Innovation Project of Hunan (Grant no. CX20190794). The authors are grateful for this financial support.

\section{References}

[1] C. Yuan, L. Fan, J.-F. Cui, and W.-J. Wang, "Numerical simulation of the supporting effect of anchor rods on layered and nonlayered roof rocks," Advances in Civil Engineering, vol. 2020, Article ID 4841658, 14 pages, 2020.

[2] J. Coggan, F. Gao, D. Stead, and D. Elmo, "Numerical modelling of the effects of weak immediate roof lithology on coal mine roadway stability," International Journal of Coal Geology, vol. 90-91, no. 91, pp. 100-109, 2012.

[3] I. Khalymendyk and A. Baryshnikov, "The mechanism of roadway deformation in conditions of laminated rocks," Journal of Sustainable Mining, vol. 17, no. 2, pp. 41-47, 2018.

[4] R. C. Liu, N. Huang, Y. J. Jiang, W. J. Hong, and Y. Y. Li, “A numerical study of shear-induced evolutions of geometric and hydraulic properties of self-affine rough-walled rock fractures," International Journal of Rock Mechanics and Mining Sciences, vol. 127, pp. 1-7, 2020.

[5] S. Hussian, N. Mohammad, Z. U. Rehman et al., "Review of the geological strength index (GSI) as an empirical classification and rock mass property estimation tool: origination, modifications, applications, and limitations," Advances in Civil Engineering, vol. 2020, Article ID 6471837, 18 pages, 2020.

[6] S. Liu, Z. J. Wan, Y. Zhang, S. F. Lu, and Z. P. Wu, "Research on evaluation and control technology of coal pillar stability based on the fracture digitization method," Measurement, vol. 158, pp. 1-8, 2020.

[7] C. Yuan, Y. N. Guo, W. J. Wang, L. M. Cao, and C. Huang, "Study on 'triaxial loading-unloading-uniaxial loading' and microscopic damage test of sandstone," Frontiers in Earth Science, vol. 8, pp. 1-11, 2020.

[8] F. Q. Gong, W. X. Wu, T. B. Li, and X. F. Si, "Experimental simulation and investigation of spalling failure of rectangular tunnel under different three-dimensional stress states," International Journal of Rock Mechanics and Mining Sciences, vol. 122, pp. 1-14, 2019.

[9] F. Gong, J. Yan, X. Li, and S. Luo, "A peak-strength strain energy storage index for rock burst proneness of rock materials," International Journal of Rock Mechanics and Mining Sciences, vol. 117, pp. 76-89, 2019.

[10] F.-Q. Gong, Y. Luo, X.-B. Li, X.-F. Si, and M. Tao, "Experimental simulation investigation on rockburst induced by spalling failure in deep circular tunnels," Tunnelling and Underground Space Technology, vol. 81, pp. 413-427, 2018.

[11] F.-Q. Gong, X.-F. Si, X.-B. Li, and S.-Y. Wang, "Dynamic triaxial compression tests on sandstone at high strain rates and low confining pressures with split Hopkinson pressure bar," International Journal of Rock Mechanics and Mining Sciences, vol. 113, pp. 211-219, 2019. 
[12] T. Yu, G. M. Zhao, X. R. Meng, X. Chen, and G. J. Li, "Stability analysis and supporting parameter design of composite roof," Coal Science and Technology, vol. 48, no. S1, pp. 17-23, 2020.

[13] S. W. Liu, S. G. Shu, H. Wang, R. K. Pan, and B. Zhang, "Analysis on main factors Controlling deformation and instability of roadway's composite roof in mining areas," The Chinese Journal of Geological Hazard and Control, vol. 30, no. 2, pp. 83-88, 2019.

[14] J. C. Chang, "Study on complex roof support technology of mining gateway in deep mine," Coal Science and Technology, vol. 44, no. 6, pp. 60-63, 2016.

[15] J. P. Zuo, X. Wei, Y. Shi, C. Liu, M. Li, and R. H. C. Wong, "Experimental study of the ultrasonic and mechanical properties of a naturally fractured limestone," International Journal of Rock Mechanics and Mining Sciences, vol. 125, pp. 1-12, 2020.

[16] J. P. Zuo, J. H. Wen, Y. D. Li, Y. J. Sun, and L. Liu, "Investigation on the interaction mechanism and failure behavior between bolt and rock-like mass," Tunnelling and Underground Space Technology, vol. 93, pp. 1-14, 2019.

[17] D. F. Zhu, Y. H. Wu, Z. H. Liu, X. Q. Dong, and J. Yu, "Failure mechanism and safety control strategy for laminated roof of wide-span roadway," Engineering Failure Analysis, vol. 111, pp. 1-14, 2020.

[18] Y. Chen, Q. Meng, G. Xu, H. Wu, and G. Zhang, "Boltgrouting combined support technology in deep soft rock roadway," International Journal of Mining Science and Technology, vol. 26, no. 5, pp. 777-785, 2016.

[19] S.-Q. Yang, M. Chen, H.-W. Jing, K.-F. Chen, and B. Meng, "A case study on large deformation failure mechanism of deep soft rock roadway in Xin'an coal mine, China," Engineering Geology, vol. 217, pp. 89-101, 2017.

[20] H. Wang, C. Jiang, P. Q. Zheng, W. J. Zhao, and N. Li, “A combined supporting system based on filled-wall method for semi coal-rock roadways with large deformations," Tunnelling and Underground Space Technology, vol. 99, pp. 1-12, 2020.

[21] C. X. Zhao, Y. M. Li, G. Liu, and X. R. Meng, "Mechanism analysis and control technology of surrounding rock failure in deep soft rock roadway," Engineering Failure Analysis, vol. 115, pp. 1-14, 2020.

[22] W. Q. Peng, W. J. Wang, and C. Yuan, "Supporting technology research in deep well based on modified terzaghi formula," Advances in Civil Engineering, vol. 2018, Article ID 9483538, 6 pages, 2018.

[23] J. Tian and S. Gao, "Deformation and failure study of surrounding rocks of dynamic pressure roadways in deep mines," Mining Science and Technology (China), vol. 20, no. 6, pp. 850-854, 2010.

[24] H. Yan, F.-L. He, L.-Y. Li, R.-M. Feng, and P.-F. Xing, "Control mechanism of a cable truss system for stability of roadways within thick coal seams," Journal of Central South University, vol. 24, no. 5, pp. 1098-1110, 2017.

[25] W. J. Yu and F. F. Liu, "Stability of close chambers surrounding rock in deep and comprehensive control technology," Advances in Civil Engineering, vol. 2018, Article ID 6275941, 18 pages, 2018.

[26] Y. H. Yang, F. L. He, S. R. Xie, H. Q. Han, and H. B. Li, "Mechanical analysis and engineering practice of prestressed truss cable system," Coal Mine Safety, vol. 6, pp. 51-53, 2010.

[27] S. B. Zhang, Z. L. Wang, C. Ren et al., "Truss-cable compound support technology based on pre-stress attenuation theory," Coal Engineering, vol. 48, no. 6, pp. 44-47, 2016.

[28] W. Yu, B. Pan, F. Zhang, S. Yao, and F. Liu, "Deformation characteristics and determination of optimum supporting time of alteration rock mass in deep mine," (Korean Society of Civil Engineers) Journal of Civil Engineering, vol. 23, no. 11, pp. 4921-4932, 2019.

[29] C. Yuan, W. Wang, and C. Huang, "A study on the mechanism and controlling techniques of roadway deformations under high in situ stress conditions," Geotechnical and Geological Engineering, vol. 38, no. 1, pp. 605-620, 2020. 